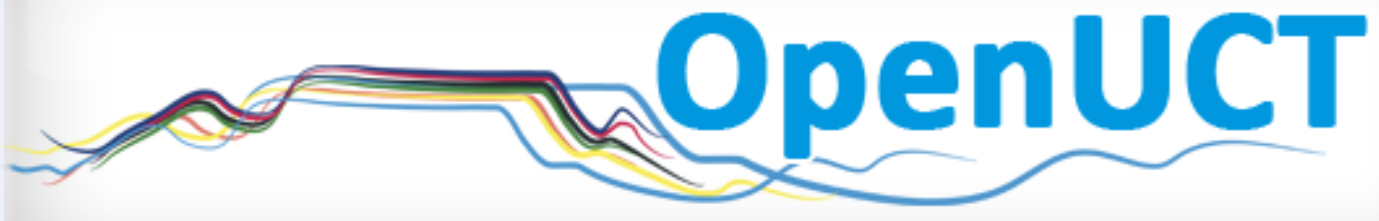

This is the author-approved manuscript version of a journal article published in:

Ng'ambi, D. \& Brown, I. 2009. Intended and unintended consequences of student use of an online questioning environment. British Journal of Educational Technology. 40(2): 316-328. DOI: $10.1111 /$ j.1467-8535.2008.00899.x.

It is made available under the terms of agreement between the author and the journal, and in accordance with the University of Cape Town's Open Access Policy for the purposes of research, teaching and private study.

http://www.openuct.uct.ac.za/sites/default/files/UCTOpenAccessPolicy.pdf 


\title{
Intended and unintended consequences of student use of an online questioning environment
}

\author{
Dick Ng'ambi and Irwin Brown
}

Dick Ng'ambi is the Principal Investigator on the Mobile Learning Project at the Centre for Educational Technology and Irwin Brown is an Associate Professor in the Department of Information Systems. Both work for the University of Cape Town in South Africa. Address for correspondence: Dick Ng'ambi, Centre for Educational Technology, P/Bag X3, Rondebosh, Cape Town, South Africa, 7701

\begin{abstract}
While supplementation of face-to-face (F2F) teaching with online engagement is increasingly common, the educators' challenge of teaching F2F personalities and facilitating online personalities has not been widely explored. In this paper, we report on a project in which 1st-year students attended F2F sessions and engaged with an anonymous online questioning environment. The differences between students' F2F and online behaviour led to intended and unintended consequences. The purpose of this paper is to explore these intended and unintended consequences of technology use. The project was undertaken over a 3-year period, starting in 2004. In 2004, a pilot project was conducted based on a class of 35 students studying a 1st-year programming course in information systems. The investigation was again conducted in 2005 for the same course, this time with 63 students. In 2006, the project was extended to a class of 610 1st-year commerce students studying an introductory information systems course. In all cases, students met F2F and when online, engaged with an anonymous Web/SMS collaborative tool. The intended consequence was that a blending of F2F with online interaction extended student engagement beyond the limitation of a classroom and provided a forum for further collaboration and consultation. The intended outcome was achieved. An unintended consequence was that the tool provided the lecturer with diagnostic information that was used to impact on pedagogical designs. This was often a result of students taking on an online personality that would very often be extremely frank and honest about the manner in which the course was conducted, and how learning was taking place. The findings show that students used the tool in ways that exceeded the envisaged intention, and student use of the tool positively
\end{abstract}




\section{Introduction}

Though desirable, it is difficult to provide personalised attention to individual students especially in large classes with over 600 students. Anecdotal evidence suggests that 1 st-year students find integration into a university culture of large classes, both daunting and challenging. At high school, students are taught in relatively small classes. Our experience of teaching 1st-year students in information systems (IS) at a medium-sized contact university was that given the little time available for students to ask questions in class, a handful of the same students asked questions while the majority remained mute. The typical face-to-face (F2F) strategy for dealing with this is that lecturers set aside consultation hours during which time students are encouraged to consult. However, consulting in this manner with more than 600 students is impractical. To overcome this limitation tutors and tutorials are used. Tutors engage with small groups of students and report back to the lecturer. However, the role of tutors as mediators creates a distance between students and the lecturer. In addition, the quality of assistance students receive from tutors is bound to vary. This challenge provides an opportunity for designing an online environment in which individual student questions can effectively be addressed directly by the lecturer, and the educator can get feedback from the artefacts of student engagement. According to Lea (1991), computer mediated communication (CMC) creates conditions for reduced self-regulation and reduced selfawareness. We infer from Lea's (1991) argument that use of CMC for student support may not therefore result in a singular unified purpose for usage, hence the possibility of disparities between intended and unintended uses.

In this paper, we report on the use of an anonymous consultation tool, the dynamic frequently asked questions (DFAQ). The intended purpose (from the teacher's viewpoint) of introducing the tool was to give students an alternative space through which they could anonymously post questions and receive responses from both the lecturer and peers concerning course content. Unintended consequences may arise from the absence of social and contextual conditions in the CMC environment. The purpose of this paper is to explore these intended and unintended consequences of using CMC for anonymous knowledge sharing. The theory of communicative rationality (Habermas, 1984 ) is used to frame our understanding of these consequences of use.

The rest of the paper is organised as follows. First is a discussion on the theoretical underpinning of the paper. Next, further details are provided about the tool. The research methodology is described thereafter, and key observations are outlined. These observations are discussed, and then the paper concluded.

\section{Theoretical underpinning}

We draw our theoretical lens from Jurgen Habermas' theory of communicative rationality (Habermas, 1984), which postulates that rationality is not about the possession of knowledge but about how 'speaking and acting subjects acquire and use knowledge' (p. 8). According to Habermas (1984), knowledge has a propositional structure and can be represented in the form of statements. We infer from Habermas (1984) that student questions are representations of the search for knowledge, and embodied in questions is 
implicit knowledge about levels of students' current understanding. Accepting this argument, it follows that student levels of understanding can be deduced from questions asked. The communicative rationality is dependent on the knowledge in which it is embodied. In other words, the speaking and acting subjects acquire and use knowledge through construction and deconstruction of meanings embodied in statements authored either by themselves or by other subjects. It can thus be argued that knowledge can be acquired through unpredictable actions of interacting subjects leading to both intended and unintended consequences. This paper is concerned with the difference between the educators' expectations of how students were to acquire and use an online tool (educator's perception of educational uses) for educational purposes and how students actually used the tool (students' perception of educational uses). The underlying argument of the paper is that communicative rationality creates a disjuncture between the educators' notions of educational use of an online tool and students' 'educational uses'.

Although unintended consequences may lead to opportunistic learning, it is difficult to understand how social contexts produce and reproduce unintended consequences, and how unintended consequences are drawn upon to shape human actions. Jones (1999) argues that human agents in their actions draw upon social structure, and the actions of humans in social contexts serve to produce, and reproduce, the social structure. Jones' (1999) argument suggests that online personalities produce online social structures and the social structures are further drawn upon during online interaction. These notions serve as the basis for making sense of and understanding the usage of online $\mathrm{CMC}$ tools and the consequences, both intended and unintended. In the next section, a special purpose CMC tool, DFAQ, which was used both as a research instrument and as a medium of social interaction is described.

\section{Dynamic frequently asked questions tool}

A DFAQ tool, designed and developed at the University of Cape Town, is a special purpose anonymous consultation environment for students (Ng'ambi, 2003; Ng'ambi, 2004; Ng'ambi \& Hardman, 2004). Through DFAQ, an anonymous web-based program and mobile phones' short message services (SMS), students consult one another and with a lecturer ( $\mathrm{Ng}$ 'ambi, 2003). DFAQ is an educative, social and communicative space, and dynamically creates a knowledge resource from student consultations. When a question is posted through the website interface, DFAQ notifies the lecturer via email and, where necessary, via SMS on their mobile phones. Questions can also be posted using SMS. The seamless interface of the Web and SMS means that users with Internet access (usually through institutional computer laboratories) can engage with those on the move whose only connection off campus might be through a mobile phone. DFAQ therefore provides an anywhere, anytime consultation environment. Responses to questions are entered through the web interface and a copy is sent via email or SMS to the poster of the question. Users who post questions from their mobile handsets receive responses via SMS. A lecturer has three ways of participating in DFAQ, ie, (1) by choosing to respond to a question, or (2) by commenting on responses from other students, or (3) by acknowledging and appreciating useful feed- 


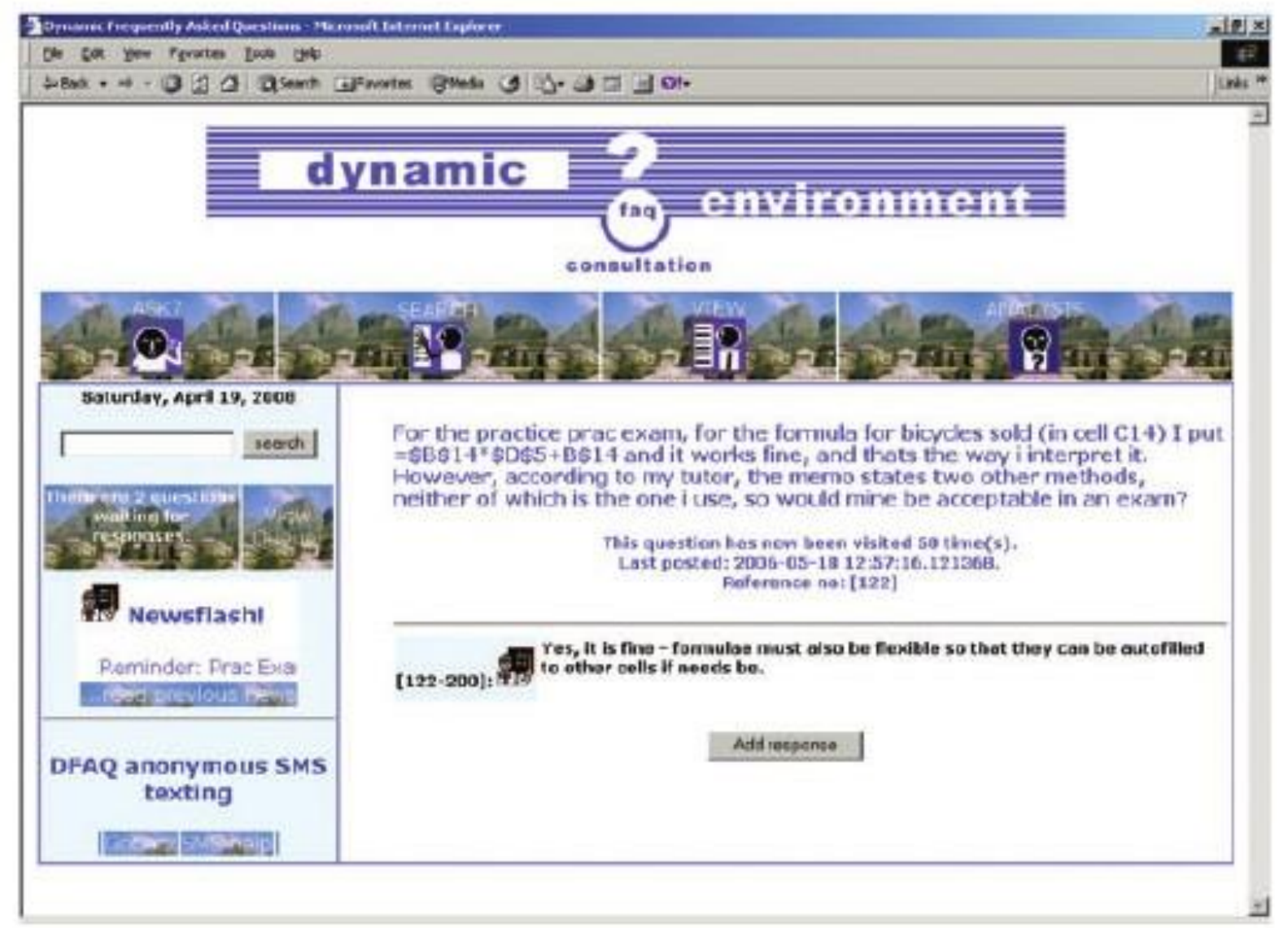

Figure 1: Part of dynamic frequently asked questions interface

back from student responses. An icon appears next to a lecturer's response to indicate to students that postings are from a trusted source. The lecturer's response is therefore not anonymous. It nevertheless allows students with some degree of comfort concerning the official response to a query. The students' queries and responses remain anonymous. This is particularly important for empowering students who would otherwise feel marginalised by dominant voices. Both the questions and responses become artefacts accessible by other students through DFAQ. The value of DFAQ lies in supporting learning both on and off-campus through anonymous consultations on the part of students. DFAQ is available 24 hours, 7 days a week, and gives students the opportunity to learn from answers to questions other students posed. The questions most frequently visited and responded to are determined through an analysis feature of DFAQ, available to students from the website navigation bar. A search facility enables students to find previous questions and answers on specific topics. Figure 1 depicts a part of the DFAQ interface.

\section{Research methodology}

This study was founded on an interpretive paradigm as it sought to understand the social reality from students' standpoint on using an online tool intended for educational purposes. This is consistent with Garrick's (2000) argument that an 'individual's expe- 
rience is best understood from the standpoint of the social world of that individual' (p. 209). The individual's social world suggests that there are multiple interpretationsthere is no single social reality. Hirschheim (1985) point out, and rightly so, that 'knowledge about human means and ends is not easily obtained because reality is exceedingly complex and elusive. There is no single reality, only different perceptions about it.' (p. 74).

The research project ran over a 3-year period with a pilot study in 2004, a follow-up in 2005 and a main study in 2006. The tool was also used in other courses in the department and, indeed, the university. In 2004, the pilot involved a 1st-year programming course in IS with 35 registered students. In 2005, the project was repeated for the same course, but this time there were 63 students. In 2006, the project was extended to 610 1 st-year students registered for an introductory IS course in a Commerce faculty. In all classes, there were both males and females. Students had access to DFAQ through the web and/or through mobile phones. The intended educational use of DFAQ was explained to students at the beginning of the courses and students were invited to make use of the tool.

Narrative analysis of student postings in DFAQ was used to unravel intended and unintended consequences. In this regard, postings are viewed as conversations in which students 'listen' to various stimuli of their own social world as well as commentate (narrate) their own experiences.

\section{Case description 2004 and 2005 cases}

In the 2004 pilot study and the 2005 follow-up, the DFAQ was intended to serve as a collaborative tool for an IS commercial programming course. This was an introductory semester course for students wishing to major in IS. The language used to teach programming was Visual Basic, using the Microsoft Vb.NET development environment. There were 35 students registered for the course in 2004 and 63 in 2005. The convenor (one of the authors in this case) had overall responsibility for the course. Details on how the courses were structured are available in the Appendix 1. This included assigning responsibilities, preparing assignments, tests, tutorials and examinations as well as liaising with lecturers and tutors. Thus, the lecturer and tutors interacted with the students' F2F personae. The student assessments served as a vehicle through which to consolidate understanding of concepts, provide feedback to students and allow lecturers/convenor to gain insight into student learning difficulties. The kind of learning taking place was primarily cognitive. Most of the tasks were conducted and assessed individually. There were some projects that were conducted in pairs or groups. Although lecturers had frequent contact time with students, there was limited time for collaboration and consultation during F2F interactions. To this end, the purpose of the DFAQ was to provide students with anywhere, anytime engagement with learning materials and allow the outcome of consultation to become a resource to the rest of the class. It was during the use of DFAQ that students' personae seemed to differ from their F2F ones. 


\section{6 case}

In 2006, participants were 1st-year students registered for an introductory course in IS in the commerce faculty. There were 610 students. As in 2004 and 2005, learning was primarily cognitive. All assessments were carried out individually. The convenor, in this instance, did most of the lecturing. The sheer number of students made it impossible to answer all questions that students had at the end of class sessions, or to cater for all students during consultation hours. Thus, the lecturer's intention for introducing DFAQ in the course was similar to that of the 2004 and 2005 cases.

\section{Observations}

In this section, some messages posted by students through the DFAQ tool are analysed. The use of DFAQ depended on when a student had a question to ask. The use was therefore in an authentic learning context. For this reason, we saw the artefacts as representing 'stories' of student learning experience. Students understood that DFAQ mediated interaction with the lecturer and peers. The use of DFAQ was informal and uncontrolled. New questions waited in a publicly visible queue for a response and DFAQ automatically triggered an email notification to the course convenor. Optionally, the course convenor received SMS notifications. Questions would be responded via SMS or from the DFAQ queue. When a question received a response, it was sent to the author either via email or SMS, depending on whether that question was posted from the web interface or mobile phone. Questions became headers and responses were threads. The user could search for a part of a keyword in either the question or response.

During the main study in 2006, there were 610 students registered on the course. It was a semester course run from February to June. The first posting into DFAQ was on February 8 and the last posted on June 19. One hundred twenty-four questions were posted during the course. A total of 221 responses to questions were posted and had a total of 5120 hits (ie, a measure of times questions were read). These hits included access by the lecturer and the original questioner. Table 1 shows how students engaged with DFAQ during the semester, type of questions posted, number of questions posted, number of responses and monthly hits. For example, the six questions posted in February generated 307 hits. The number of hits served as indicator of the interest a question attracted in a class of 610 students.

The type of questions and comments changed throughout the semester. When the course began, students tended to ask questions about how the course related to their personal career choices. They also asked questions about techniques of studying the course. Some of these questions could have been signs of anxiety, given that it was, for most, their first year at a university. As the course progressed, students started posting insightful, and sometimes, complex cognitive questions. A few of these are outlined in the next section. These sorts of questions were sandwiched with affective questions and non-academic questions. 
Table 1: Type of questions posted and DFAQ activities during the 2006 semester

\begin{tabular}{lll}
\hline Month & \multicolumn{1}{c}{ Type of questions } & \multicolumn{1}{c}{ Observations } \\
\hline February & Questions about information systems & 6 questions posted \\
& as a career and how to study & 9 responses \\
March & Acme academic questions & 307 hits \\
& Academic questions & 32 questions posted \\
& Course admin questions & 51 responses \\
April & Observation type of questions & 1227 hits \\
& Test prep questions & \\
& Questions relating to test written & 38 questions posted \\
May & Affective type of questions & 73 responses \\
& Observation type of questions & 1482 hits \\
& Academic questions & 38 questions posted \\
& Course admin courses & 75 responses \\
June & Exam prep questions & 1803 hits \\
& Non-academic questions & \\
& Exam prep questions & 10 questions posted \\
& & 13 responses \\
\hline
\end{tabular}

DFAQ, dynamic frequently asked questions.

\section{Artefact analysis}

The text analysed below is unedited to show both that students were relaxed and honest in their communication. The students spoke English as either a first, second or third language. This analysis revealed instances of both intended and unintended consequences of tool use.

The following question was chosen as it represented many similar questions that focused on concepts covered in F2F sessions.

S1... I would like to find out if arrays are a pre-requisit for assignment 2. Would it be posible to use data files rather than arrays because it make for more stable and managable programming.

The significance of the question lay in that the student not only asked a question but also motivated the question, exposing his or her level of knowledge. The question revealed that the student understood the concept of files although one could not tell whether the student understood arrays. The student wondered about the objective of the learning task based on his or her understanding of the limitations of arrays. The question was within the expected use of DFAQ, as asking questions and seeking clarity was an expected use. However, it was also noteworthy that embodied in a question was knowledge about the students' understanding of a concept. Access to this knowledge made designs of individualised intervention possible. The lecturer had not considered the option of data files because the use of data files was not on the curriculum at 1 st-year level. The student reasoned that use of arrays could be disadvantageous because array data was stored in volatile memory. The posting revealed the option of 
changing requirements to allow students to use data files as well. In response to the question, the lecturer commended the student's reasoning, and explained that the aim of the exercise was to ensure that students grasped the concept of arrays and that data files were to be covered in the second year. It was unexpected (an unintended consequence) that use of DFAQ would impact curriculum and pedagogy in this way.

Other questions provided feedback to the educator on the general organisation of the course. Traditionally, feedback information on the course would only be obtained through course evaluations at the end of a semester or academic year. The use of DFAQ through anonymous communication provided an effective space for students to express themselves honestly. Having a tool that would provide an ongoing formative evaluation of the courses was not intended when the tool was introduced. One of the questions that served as useful feedback in this regard is displayed below. It was concerned with how tutors handled the tutorials.

S2. ... concerning some tutors. they act very much like some school teachers. they pay special attention to some students. im sure that im not the only one who have noticed that. full answers are given to such students, and half to others. please AB [lecturer] speak to them. we should be treated equally regardless of anything.

Being a 1st-year course, the comparison of tutors to school teachers was understood in context of high school being the most recent educational experience. In order to add validity to the complaint, the author argues that there could be other students who shared the observation. In articulating the complaint, the student refers to tutors as 'they' and other students as 'we' arguing that he or she was not the only one to have observed the situation. Although the reference to a community of tutors and a community of students could appear to be a generalisation, the statement shows that DFAQ was a community space in which students felt a sense of social responsibility. The author was persuading the reader not to see the complaint as an isolated case. The amount of support this posting received from other students showed that this concern was shared among other students. However, F2F interaction between tutors and students did not give any clues that there was a problem. Despite the posting being anonymous, the author was not willing to identify the alleged tutors involved or the alleged students that received favours but appealed to the educator to address the problem. The question attracted supportive comments from members of the class. The lecturer commented on the responses and arranged a meeting with tutors to address the allegations. There was another posting that seemed to support the allegations and this was about alleged tutors' favouritism.

S3. ... i just want to complain about last thursdays tut. we had very few tutors whom all occupied just one lab, it was unfair that some of us had to wait for like 15 mins before we could get help.some tutors spent too much time with one student.i hope that was the last time as it was the first ...

In the above statement, the author began by stating explicitly that they were complaining. The similarity between S3 and S2 was that both involved tutors' behaviour. Tutors 
had access to DFAQ and could read the contributions. It was useful to observe how DFAQ helped students to surface inner feelings that altered F2F behaviours. The Positive change in tutor-student interaction that resulted from these postings is beyond The scope of this paper. Through DFAQ, the course convenor had immediate feedback On how the course was running. Such information would otherwise have only been identified, if at all, in course evaluations at the end of the course during which time it would have been too late to make changes that would benefit the current cohorts of students. Notwithstanding some students would not bother to give such information during evaluations. Many students are reluctant to vent complaints openly to lecturers or convenors. Some of the decisions the convenor took included hiring of additional tutors and ensuring adequate distribution across different labs. The super tutor (ie, head tutor) was asked to ensure that tutors did not jump between labs, but remained in the lab to which they were assigned. DFAQ impacted on teaching strategies and course organisation, leading to an enhanced student learning experience. This type of impact was not anticipated when DFAQ was introduced (another unintended consequence).

Student honesty was not limited to subsidiary issues of the course. There were questions that brought to light fundamental curriculum related concerns and the question below is one such:

S4. what is the purpose of the prep tut because it does nothing in as far preparing one for the actul tut.yes the pracs on tuesdays and thursdays are very much related to what the actual tut is.the tuts are really not difficult,coz they are not meant to be.but i think it could be better if the whole structure of the prep tut could be similar to the actual tut. the thing it becomes a bit tricky to combine what is done in pracs during the actual tut. my main point here is that i could be a lot better if the prep tut could have a similar structure to the actual tut.

In the above question, the student pointed out the dichotomy between the structure of preparatory tutorial and actual tutorial. The confidence with which students commented on issues when online was impressive. The same confidence was not always evident in F2F sessions, showing two personae at play. DFAQ provided learners with confidence to comment on issues of the course that are otherwise difficult to comment on without being asked. This was significant in that in F2F environments, students would sometimes have had to be prompted to comment on some of the issues that flowed spontaneously when online. This therefore served as a useful contribution to the course by learners. The lecturer posted messages to acknowledge feedback in DFAQ. Acknowledgements were also made during F2F meetings with students whereby affirming the contributor and boosting the class' confidence in using DFAQ. It can therefore be inferred that while DFAQ was used as an educative space for learners, it also created useful reflection space for the educator who had to confront and deal with his or her own assumptions. This question (S4) resulted in preparation tutorials being redesigned so as to be of similar format to actual assessed tutorials, thus better serving their purpose.

Among other observations was the disjuncture between performance in assignments and tests on one hand and learning on the other. The educator's underlying assumption 
in preparing assignments was to help students learn and that students who completed assignments and did well had learnt the material. Thus, through assignments students received feedback on their learning and the educator understood what students were still struggling with. These assumptions were disputed through the following posting that appeared in another 1st-year IS course, which also made use of DFAQ:

S5. ... i am finding one part of the lectures nice and interesting,but the theory makes no sense i do my assignmsnts and i pass,but if $u$ asked what $i$ just handed in i wouldnt be able to explain on my own.Ive never done computer before so plz go slow with the data inputs and whatevers ...

The above statement was profound in that it questioned educators' assumptions about how students learnt. Embodied in the statement was the fact that an educator could be deceived to believe the relation between passing assignments and grasping materials. The anonymity of DFAQ afforded honest communication from the side of learners and allowed the educator to confront his or her own assumptions head-on. That the learners were honest about their own learning was again a positive yet unintended consequence of using the tool. It was inferred from the posting that the student was asking for tighter integration between theory and practice.

\section{Discussion}

DFAQ provided a way of determining popularity of postings by way of indicating the number of times questions were looked up. Using this feature, it was observed that there was just as much interest in academic questions (eg, S1) as there was on questions that involved complaining about the course (eg, S2 and S3). The preconception was that students would use the tool to post academic questions and engage in direct learning activities. Actual findings were that students were just as concerned about how teaching activities were conducted and the general administration of the learning activities (eg, S4). The intention of using the DFAQ tool was to blend F2F and online interaction, and extend student engagement beyond the limitation of a classroom. This intended purpose was fulfilled as the students made frequent use of the tool to post questions and comments regarding course content. Questions were responded to by other learners, as well as by the lecturers. The tool afforded anonymity to students while allowing for official responses from the lecturers. The questions and comments became a repository of knowledge, which was regularly visited by students. The unintended consequence was that DFAQ highlighted what students-and not the lecturers-regarded as important. The DFAQ tool therefore provided a means for formative evaluation to take place. Any disjuncture between learning and outcomes could be dealt with as concerns were raised through the DFAQ tool. This was to the direct benefit of students in the cohort at hand, as opposed to making changes for the benefit of a following year's intake of students. This typically occurs when there is only an end-of-course summative evaluation. Pedagogy was continuously revisited, allowing students' views to shape how the convenor and lecturers designed, organised and administered learning activities. For example, S2 and S3 provided insight on the role and effectiveness of tutors. Needless to say, it would have been difficult for the convenor or lecturer to (1) gain insight in the behaviour of tutors and (2) determine that students were not learning despite passing 
the assignments and tests, without the use of DFAQ. Negative unintended consequences included students abusing the anonymity afforded by the tool to post insults directed at either lecturers or other students. There was a facility, however, that allowed lecturers to delete such postings before they entered the knowledge repository. Students were aware that postings were visible to all that visited the site. As such, the content of their postings was in the public domain.

\section{Conclusion}

The paper has described a 3-year project in which educators' pre-conceptions of what constituted educational use of DFAQ (intended consequences) and students' actual educational use of the tool (intended and unintended consequences) were highlighted. The DFAQ project addressed the problem of social imbalances (ie, the dominant and the dominated) in multicultural classes through the creation of a safe space to empower the voiceless students. As a consequence, anonymity of sources of postings was critical. Users posted questions and responded to others' questions using a web browser or from their mobile phones. The paper has discussed some of the postings from individual students. It is worth noting that a single student could post a question that was potentially of interest to over 600 other students. DFAQ tracked the number of hits per question and facilitated question-focused discussion. To the extent that authors of questions received answers to their questions, and that their questions impacted on how the course was taught, suggests that the minority were empowered. The privacy of the mobile phone augmented the anonymity feature of DFAQ. The paper has also shown that lecturers and students are speaking and acting subjects whose acquisition and use of knowledge cannot be predetermined-hence unintended consequences of tool use. Although the intention in setting up DFAQ was to scaffold individual student learning, the convenor did not expect that the tool would provide for continuous formative evaluation through useful feedback about the tutors, pedagogical designs, course administration and insight into student learning. The students' use of DFAQ allowed the educator to make pedagogical and administrative changes to the courses so as to be of benefit to the current student cohort. This served to confirm that there was no single social reality of use of an educational tool and that technologies in use may serve sometimes very different purposes to those originally intended by designers.

\section{References}

Garrick, J. (2000). The construction of 'working knowledge' and (mis)interpretive research. In J. Garrick \& C. Rhodes (Eds), Research and knowledge at work-perspectives, case-studies and innovative strategies (pp. 203-216). London: Routledge.

Habermas, J. (1984). The theory of communicative action. Vol. 1: Reason and the rationalization of society. (T. McCarthy, Trans.), London: Heinemann Educational Books.

Hirschheim, R. A. (1985). Information systems epistemology: an historical perspective. In E. Mumford, R. Hirschheim, G. Fitzgerald \& T. Wood-Harper (Eds), Research methods in information systems (pp. 13-36). Amsterdam: North-Holland.

Jones, M. (1999). Structuration theory. In W. L. Currie \& B. Galliers (Eds), Rethinking management information systems (pp. 103-135). Oxford: Oxford University Press.

Lea, M. (1991). Computer-mediated communication-de-individuation and group decisionmaking. International Journal of Man-Machine Studies, 34, 283-301. 
Ng'ambi, D. (2003). Students helping students learn —-the case for a web-based dynamic FAQ environment. In Proceedings of the International Association of Science and Technology for Development (IASTED) Conference on Information and Knowledge Sharing, 22-27 August (pp. 293298). Scottsdale: ACTA Press.

Ng'ambi, D. (2004). Towards an organizational intelligent framework based on Giddens' structuration theory: a case of using an organizational memory system-DFAQ. In IFIP world congress proceedings of the symposium on professional practice in Artificial intelligence, 17-19 November. Toulouse: Kluwer.

Ng'ambi, D. \& Hardman, J. (2004). Towards a knowledge-sharing scaffolding environment based on learners' questions. British Journal of Educational Technology, 35, 2, 187-196.

\section{Appendix 1}

2004 and 2005 case studies

The courses were structured as follows:

The weekly F2F schedule:

\begin{tabular}{|l|l|}
\hline MON & 1 hour Concepts lecture \\
\hline MON & 1 hour Repeat tutorial (optional) \\
\hline TUE & 2 hours Practical session \\
\hline WED & 1 hour Concepts lecture \\
\hline THU & 2 hours Practical session \\
\hline THU & 1 hour Assessed tutorial \\
\hline
\end{tabular}

Student assessment:

\begin{tabular}{|l|l|}
\hline Assessed tutorials & $10 \%$ \\
\hline Practical session attendance & $4 \%$ \\
\hline 2 Concept tests & $18 \%$ \\
\hline 2 Practical assignments & $18 \%$ \\
\hline Final concept exam & $50 \%$ \\
\hline
\end{tabular}

Staffing:

1 Convenor

1 Lecturer (taught concepts and ran practical sessions)

1 Teaching assistant (taught some concepts but mainly ran practical sessions)

Several tutors (to run tutorials and assist with practicals)

\section{6 case study}

The course was structured as follows:

The weekly F2F schedule:

\begin{tabular}{|l|l|}
\hline MON & 1 hour Concepts lecture \\
\hline TUE & 1 hour Concepts lecture \\
\hline TUE & 1 hour Practical session \\
\hline WED & 1 hour Practical demonstration in lecture theatre \\
\hline
\end{tabular}




\begin{tabular}{|l|l|}
\hline THU & 1 hour Practical demonstration in lecture theatre \\
\hline FRI & 1 hour Review session in lecture theatre \\
\hline
\end{tabular}

Student assessment:

\begin{tabular}{|l|l|}
\hline Practical tutorials & $6 \%$ \\
\hline 2 Practical tests & $10 \%$ \\
\hline 2 Concept assignments & $4 \%$ \\
\hline 2 Concept tests & $10 \%$ \\
\hline Final practical exam & $30 \%$ \\
\hline Final concept exam & $40 \%$ \\
\hline
\end{tabular}

Staffing:

1 Convenor/lecturer

2 Lecturers (taught some concepts and conducted practical demonstrations)

2 Teaching assistants (conducted review sessions)

Several tutors (to run tutorials and assist with practicals) 